\title{
Optimization of Enzymatic Synthesis of Palm- based Kojic Acid Ester Using Response Surface Methodology
}

\author{
Siti Efliza Ashari ${ }^{1}$, Rosfarizan Mohamad ${ }^{1,2 *}$, Arbakariya Ariff ${ }^{1,2}$, Mahiran Basri ${ }^{2,3}$ and \\ Abu Bakar Salleh ${ }^{2,4}$ \\ ${ }^{1}$ Department of Bioprocess Technology, Faculty of Biotechnology and Biomolecular Sciences, Universiti Putra Malaysia, 43400 UPM \\ Serdang, Selangor, MALAYSIA \\ ${ }^{2}$ Laboratory of Industrial Biotechnology, Institute of Bioscience, Universiti Putra Malaysia, 43400 UPM Serdang, Selangor, MALAYSIA \\ ${ }^{3}$ Department of Science, Faculty of Science, Universiti Putra Malaysia, 43400 UPM Serdang, Selangor, MALAYSIA \\ ${ }^{4}$ Department of Biochemistry, Faculty of Biotechnology and Biomolecular Sciences, Universiti Putra Malaysia, 43400 UPM Serdang, \\ Selangor, MALAYSIA
}

\begin{abstract}
Kojic acid monooleate is a fatty acid derivative of kojic acid which can be widely used as a skin whitening agent in a cosmetic applications. In avoiding any possible harmful effects from chemically synthesized product, the enzymatic synthesis appears to be the best way to satisfy the consumer demand nowadays. The ability of immobilized lipase from Rhizomucor meihei (lipozyme RMIM) to catalyze the direct esterification of kojic acid and oleic acid was investigated. Response Surface Methodology (RSM) and 5-level-4-factor central composite rotatable were employed to evaluate the effects of synthesis parameters such as enzyme amount $(0.1-0.4 \mathrm{~g})$, temperature $\left(30-60^{\circ} \mathrm{C}\right)$, substrate molar ratio $(1-4 \mathrm{mmol}$, kojic acid:oleic acid) and reaction time $(24-48 \mathrm{~h})$ on percentage molar conversion to kojic acid monooleate. Analysis of the product using TLC, GC and FTIR showed the presence of kojic acid monooleate. The optimal conditions for the enzymatic reaction were obtained after analysis with backward elimination using $0.17 \mathrm{~g}$ of enzyme and $4 \mathrm{mmol}$ of substrate at $52.50{ }^{\circ} \mathrm{C}$ for $42 \mathrm{~h}$. Under these conditions the esterification percentage was $37.21 \%$. The results demonstrated that response surface methodology can be applied effectively to optimize the lipase-catalysed synthesis of kojic acid monooleate. The optimum conditions can be used to scale up the process.
\end{abstract}

Key words: kojic acid monooleate, lipase, optimization, Response Surface Methodology

\section{INTRODUCTION}

Kojic acid, 5-hydroxy-2-(hydroxymethyl)-1,4-pyrone, is a fungal metabolite produced by many species of Aspergillus oryzae, Acetobacter and Penicilium camembertii. It is widely distributed in food materials such as soy sauce, miso and sake which endowing them with a special taste, colors and flavors ${ }^{1)}$. Kojic acid also acts as a precursor for flavor enhancers for example the synthesis of maltol which is useful for improving the flavors of various food products and as an ingredient of perfumes and flavors ${ }^{2)}$. Recently, kojic acid is primarily used as a basic ingredient for skin whitener in cosmetic cream where it used to block the formation of pigment by the deep cells on the skin ${ }^{3}$. Cosmet- ics containing skin whitening agents have attracted the attention of women in Asian countries and become best selling skin care products. However, kojic acid is water soluble, and its instability has been a problem in cosmetic $u^{4)}$. To improve the lipophilic properties of kojic acid, esterification with fatty acid to synthesize kojic acid ester is a suitable and attractive method ${ }^{5}$. Due to that, it has now been found that kojic acid ester can produce excellent effects in whitening the skin and in anti-suntan effect. Moreover, the esterification product has an excellent sta-

Nomenclature: TLC: Thin layer Chromatography, FT-IR: Frontier Transform Infrared Radiation, GC: Gas Chromatography

*Correspondence to: Rosfarizan Mohamad, Department of Bioprocess Technology, Faculty of Biotechnology and Biomolecular Sciences, Universiti Putra Malaysia, 43400 UPM Serdang, Selangor, MALAYSIA.

E-mail: farizan@biotech.upm.edu.my

Accepted May 19, 2009 (recieved for review April 20, 2009)

Journal of Oleo Science ISSN 1345-8957 print / ISSN 1347-3352 online

http://www.jstage.jst.go.jp/browse/jos/ 


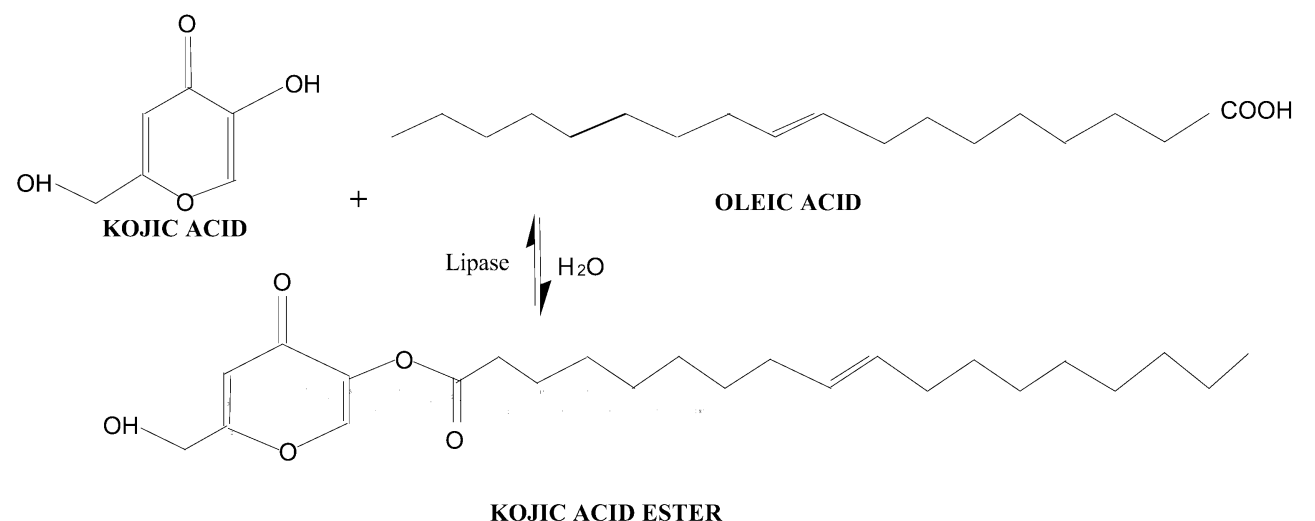

Fig. 1 Synthesis of Kojic Acid Monooleate.

bility to $\mathrm{pH}$, heat and light thus resulting in an excellent storability and oil solubility that can be more easily absorbed into the skin when it is incorporated in a cream ${ }^{6}$. Traditionally, kojic acid ester could be synthesized by a chemical method. However, the chemically synthesized product is expensive and unnatural. The high temperature process can lead to degradation of the esters and undesired side product, thus resulting high cost of energy ${ }^{7,8)}$ and low production of ester yield ${ }^{9}$. Due to steady growing demand for natural materials, the biosynthesis of such esters by lipase-catalyzed reactions, under mild conditions, has become a current commercial interest. An optimized enzymatic synthesis of kojic acid esters with improved yield at reduced cost in the most favorable conditions would benefit to the manufacturers and be more appealing to the consumer.

Several studies have been reported for production of kojic acid ester. The parameters affecting involved reaction time, temperature, enzyme amount, added water content and substrate molar ratio. Enzymatic synthesis of kojic acid monolaurate using immobilized lipase from $P$ seudomonas cepacia has been previously reported by Liu and Shaw ${ }^{10)}$. They found that reaction time and added water content were the most important variables in production of kojic acid monolaurate. Water plays multiple roles in lipasecatalyzed esterifications performed in non-conventional media and it is well-known that the water content affects the equilibrium conversion of the reactions. However, different finding was reported by Kamarudin et al. ${ }^{11)}$. They reported that no significant effect on added water content in production of kojic acid monooleate by using immobilized lipase from Rhizomucor meihei (Lipozyme RMIM). Particularly, Lipozyme performed best under anhydrous conditions for the esterification of kojic acid with oleic acid. It is possible that kojic acid monooleate is easily hydrolyzed by lipase without addition of water or even in small amount of water. Furthermore, in order to characterize the structure, kojic acid ester could be revealed via
TLC, FT-IR and GC spectroscopy.

Few studies were applied systematically using statistical methods in order to investigate the combination of those parameters for the best production of kojic acid ester process. Response Surface methodology (RSM) is essentially a particular set of mathematical and statistical methods for designing experiments, building models, evaluating the effects of variables and searching optimum conditions of variables to predict targeted responses. The main advantage of RSM is the reduced number of experimental trials needed to evaluate multiple factors and their interactions. The study of the individual and interactive effects of these factors will be helpful in efforts to find the target value ${ }^{12)}$. Hence, RSM provides an effective tool for investigating the aspects affecting desired response if there are many factors and interactions in the experiment.

The present work focused on the reaction parameters that affect the synthesis of kojic acid monooleate catalyzed by immobilized lipase from Rhizomucor meihei (Lipozyme RMIM) in acetonitrile (Fig. 1). Palm oil was chosen as the reactant as an alternative source of kojic acid ester synthesis due to its competitive price and availability. Our objectives were to better understand the relationships between various reaction variables (i.e., time, temperature, substrate molar ratio and enzyme amount) and the response (molar conversion); and to obtain the optimum conditions for kojic acid monooleate synthesis by using central composite rotatable design (CCRD) and RSM. To our knowledge, no reports on the enzymatic synthesis of kojic acid monooleate using RSM have been reported in literature.

\section{MATERIALS AND METHODS}

\subsection{Materials}

Immobilized lipase (triacylglycerol hydrolase, EC 3.1.1.3: Lipozyme RMIM 150 IUN/g) from Rhizomucor meihei supported on macroporous anionic exchange resin was 
purchased from Novo-Nordisk (Denmark). Kojic acid (purity, 98 \%) was kindly donated by Tokyo Kasei Kogyo Co., Ltd. (Japan). Oleic acid (purity, 99 \%) was obtained from Southern Edible Oil Sdn. Bhd., Selangor, Malaysia. Acetonitrile, hexane, ethyl acetate and iodine were obtained from Merck (Germany). Meanwhile, glycerol tributyrate, used as internal standard in gas chromatography analysis was obtained from Sigma-Aldrich (USA). All other reagents were of analytical grade.

\subsection{Enzymatic synthesis}

Different substrate molar ratio of kojic acid and oleic acid were mixed in $150 \mathrm{~mL}$ shake-flask, and $50 \mathrm{~mL}$ of acetonitrile was added as a solvent. Different amounts of lipase were subsequently added. The reaction was performed in a horizontal water bath at $150 \mathrm{rpm}$ at different temperatures and time periods (Table 1). All experiments were carried out in triplicates.

\subsection{Identification of reaction product}

The reaction was terminated by separating the enzyme

Table 1 Central Composite Rotatable Second-order Design and Experimental Data for 5-Level-4-factor Response Surface Analysis.

\begin{tabular}{|c|c|c|c|c|c|}
\hline \multirow{3}{*}{ Treatment } & \multicolumn{3}{|c|}{ Variables } & \multirow{3}{*}{$\begin{array}{c}\text { Substrate Molar } \\
\text { Ratio (mmol) } \\
\text { D }\end{array}$} & \multirow{3}{*}{$\begin{array}{l}\text { Yield } \\
(\%)\end{array}$} \\
\hline & $\begin{array}{l}\text { Time } \\
\text { (h) }\end{array}$ & $\begin{array}{c}\text { Temperature } \\
\left({ }^{\circ} \mathrm{C}\right)\end{array}$ & $\begin{array}{c}\text { Enzyme } \\
(\mathrm{g})\end{array}$ & & \\
\hline & A & B & C & & \\
\hline 1 & 30 & 52.50 & 0.17 & 4 & 0.90 \\
\hline 2 & 42 & 37.50 & 0.17 & 4 & 6.08 \\
\hline 3 & 36 & 45.00 & 0.25 & 5 & 1.73 \\
\hline 4 & 48 & 45.00 & 0.25 & 3 & 2.63 \\
\hline 5 & 36 & 30.00 & 0.25 & 3 & 0.00 \\
\hline 6 & 42 & 52.50 & 0.33 & 4 & 5.07 \\
\hline 7 & 42 & 52.50 & 0.17 & 4 & 37.21 \\
\hline 8 & 42 & 52.50 & 0.17 & 2 & 32.86 \\
\hline 9 & 30 & 52.50 & 0.33 & 4 & 4.91 \\
\hline 10 & 36 & 60.00 & 0.25 & 3 & 4.56 \\
\hline 11 & 42 & 52.50 & 0.33 & 2 & 35.18 \\
\hline 12 & 36 & 45.00 & 0.25 & 1 & 1.60 \\
\hline 13 & 36 & 45.00 & 0.25 & 3 & 1.08 \\
\hline 14 & 24 & 45.00 & 0.25 & 3 & 0.31 \\
\hline 15 & 42 & 37.50 & 0.33 & 2 & 3.09 \\
\hline 16 & 36 & 45.00 & 0.4 & 3 & 5.54 \\
\hline 17 & 42 & 37.50 & 0.33 & 4 & 2.67 \\
\hline 18 & 36 & 45.00 & 0.10 & 3 & 1.84 \\
\hline 19 & 36 & 45.00 & 0.25 & 3 & 0.93 \\
\hline 20 & 30 & 37.50 & 0.33 & 4 & 3.62 \\
\hline 21 & 30 & 37.50 & 0.33 & 2 & 0.56 \\
\hline 22 & 36 & 45.00 & 0.35 & 3 & 0.17 \\
\hline 23 & 30 & 37.50 & 0.17 & 2 & 0.29 \\
\hline 24 & 30 & 52.50 & 0.17 & 2 & 1.48 \\
\hline 25 & 30 & 52.50 & 0.33 & 2 & 0.70 \\
\hline 26 & 36 & 45.00 & 0.25 & 3 & 0.33 \\
\hline 27 & 36 & 45.00 & 0.25 & 3 & 0.86 \\
\hline 28 & 42 & 37.50 & 0.17 & 2 & 0.13 \\
\hline 29 & 30 & 37.50 & 0.17 & 4 & 7.65 \\
\hline 30 & 36 & 45.00 & 0.25 & 3 & 6.05 \\
\hline
\end{tabular}


from the mixture by filtration using a filter paper. The solvent was removed by rotary evaporator. Preliminary detection and identification of reaction product were examined by thin-layer chromatography (TLC) on pre-coated silica gel plate $\left(60 \mathrm{~F}_{254}\right)$ and developed in hexane: ethyl acetate (70:30, vol/vol). Iodine vapor was used as the detection system. Further identification was carried out by FTIR spectroscopy. Final identification was carried out by GC instrument. Analysis was done by injecting a $1-\mu \mathrm{L}$ aliquot in a splitless mode into a Shimadzu gas chromatography equipped with a flame-ionization detector. A HT- 5 fused silica capillary column $(0.30 \mathrm{~m} \times 0.53 \mathrm{~mm} \times 0.15 \mu \mathrm{m})$ was used. Injector and detector temperatures were set at $340^{\circ} \mathrm{C}$ and $350^{\circ} \mathrm{C}$ respectively. Oven temperature was programmed $70^{\circ} \mathrm{C}$ to $340^{\circ} \mathrm{C}$ at a rate of $20^{\circ} \mathrm{C} / \mathrm{min}$. The carrier gas was nitrogen. Glycerol tributyrate was added to each sample as an internal standard before sample analysis. The percent yield (molar conversion) was defined as [(mmole kojic acid monooleate/mmole initial kojic acid ) $\times 100 \%]$.

\subsection{Experimental design and statistical analysis}

A 5-level/4-factor central composite rotatable design (CCRD) was employed in this study, requiring 30 experiments. The fractional factorial design consisted of 16 factorial points, eight axial points and six center points. The variable and levels to investigate the optimal synthesis conditions were chosen on the basis of previous work ${ }^{11}$. The variable and their levels selected for the kojic acid ester synthesis were: enzyme amount (0.1-0.4 g); temperature $\left(30-60^{\circ} \mathrm{C}\right)$; substrate molar ratio $(1-4 \mathrm{mmol}$; kojic acid:oleic acid) and reaction time (24-48 h). Each independent variable was investigated at five different levels of a high $(+2)$, a moderate high $(+1)$, center points $(0)$, a moderate low $(-1)$ and a low (-2). The design of experiments employed is presented in Table 1.

A statistical software package by Design Expert Version 6.0.6 (State-Ease Inc., Statistics Made Easy, Minneapolis, MN, USA) was used to fit the second-order model to the independent variables using the following equation:

$$
y=b_{0}+\sum_{i=1}^{4} b_{i} x_{i}+\sum_{i=1}^{4} b_{i i} x_{i} 2+\sum_{i=j}^{3} \sum_{j=i+1}^{4} b_{i j} x_{i j}+e
$$

Where $\mathrm{y}$ is the independent variable (percentage yield) to be modeled, $x_{i}$ and $x_{j}$ are the independent variables (factors), $b_{0}, b_{i}, b_{i i}$ and $b_{i j}$ are the regression coefficients of the model, and e is the error of the model. An analysis of variance (ANOVA) was used to determine whether the constructed model was adequate to describe the observed data. The $R^{2}$ statistic indicates the percentage of the variability of the optimization parameters that is explained by the model. The response surface graphs were obtained using that statistical software to understand the effects of variables individually and in combination and to determine their optimum condition for production of kojic acid monooleate.

\section{RESULTS AND DISCUSSION}

\subsection{Identification of reaction product}

Products from esterification reaction between kojic acid and oleic acid catalyzed by Lipozyme RMIM were analyzed by TLC. The presence of the kojic acid ester $\left(R_{t}=0.27\right)$, oleic acid $\left(\mathrm{R}_{\mathrm{t}}=0.59\right)$ and kojic acid $\left(\mathrm{R}_{\mathrm{t}}=0\right)$ were detected as dark brown spots when visualized by an iodine reagent. Further identification of product was carried out by FTIR spectroscopy. FTIR spectra showed an intense band at around $1743 \mathrm{~cm}^{-1}$ corresponding to characteristic to the ester function $\mathrm{C}=0$. Final identification of reaction mixture was performed by GC chromatogram showed major peak of kojic acid ester presence at retention time of $15.40 \mathrm{~min}$, kojic acid at $8.20 \mathrm{~min}$, oleic acid at $10.92 \mathrm{~min}$ and an internal standard (glycerol tributyrate) at $9.20 \mathrm{~min}$.

\subsection{Model fitting and ANOVA}

According to the experimental design, the best-fitting model was determined by regression analysis and backward elimination. Initial analysis revealed that the substrate molar ratio had most negative effect $(\mathrm{p}>0.05)$ on the production of KAMO whereas all other factors had shown positive effect. Hence, the substrate molar ratio had been removed from the model due to no significant effect on the production of KAMO. Similar analysis was also reported by Kim and $\mathrm{Akoh}^{13)}$ on the optimization of phytosteryl esters production using RSM. Fitting of the data to various models (linear, two factorial, quadratic and cubic) and their subsequent ANOVA showed that the reaction of kojic acid and oleic acid were most suitably described with a two factorial interaction (2 FI) model as follows:

$$
\begin{aligned}
\text { Yield }(\%)= & +5.67+4.45 \mathrm{~A}+4.10 \mathrm{~B}-1.75 \mathrm{C}+ \\
& 6.27 \mathrm{AB}-2.59 \mathrm{AC}-1.03 \mathrm{BC}
\end{aligned}
$$

Where $\mathrm{A}$ is the time; $\mathrm{B}$ the temperature and $\mathrm{C}$ the amount of enzyme.

The fit quality of the yield model is attested with analysis of the variance (ANOVA) as revealed in Table 2 with the elimination of substrate molar ratio (D). The ANOVA analysis of the optimization study indicated that the model terms $\mathrm{A}, \mathrm{B}$, and $\mathrm{AB}$ are significant model in terms of $\mathrm{KAMO}$ production (prob $>\mathrm{F}$ is less than 0.05 ). The result also revealed that the amount of enzyme $(\mathrm{C})$ had a less significant effect $(\mathrm{p}>0.05)$.

According to the ANOVA of factors, the computed $\mathrm{P}$ value of the model is 0.0022 implying that the model is significant while the lack-of-fit is 0.080 implying that the lackof-fit is not significant relative to the pure error. The sig- 
Table 2 Analysis of Variance (ANOVA) and Model Coefficients.

\begin{tabular}{lccccc}
\hline \multicolumn{1}{c}{ Source } & Sum of squares & DF & Mean Square & F-value & P-value \\
\hline Model & 1705.22 & 6 & 284.20 & 4.96 & 0.0022 \\
$\mathrm{~A}$ & 475.17 & 1 & 475.17 & 8.30 & 0.0084 \\
$\mathrm{~B}$ & 402.87 & 1 & 402.87 & 7.03 & 0.0142 \\
$\mathrm{C}$ & 73.47 & 1 & 73.47 & 1.28 & $0.2691^{\mathrm{a}}$ \\
$\mathrm{AB}$ & 629.13 & 1 & 629.13 & 10.98 & 0.0030 \\
$\mathrm{AC}$ & 107.59 & 1 & 107.59 & 1.88 & $0.1837^{\mathrm{a}}$ \\
$\mathrm{BC}$ & 17.00 & 1 & 17.00 & 0.30 & $0.5912^{\mathrm{a}}$ \\
& & & & & \\
Residual & 1317.27 & 23 & 57.27 & & \\
Lack of fit & 723.37 & 8 & 90.42 & 2.28 & \\
Pure Error & 593.90 & 15 & 39.59 & & \\
Cor Total & 3022.49 & 29 & & & \\
$\mathrm{R}^{2}$ & 0.5642 & & & & \\
\hline
\end{tabular}

$\mathrm{DF}$, degree of freedom; Prob $>\mathrm{F}$, level of significant

$\mathrm{R}^{2}$, coefficient of determination

${ }^{\mathrm{a}}$ Not significant at $\mathrm{p}=0.05$

nificant model and non-significant lack-of-fit indicate that the model is a good fit. The fitness between the development model and experimental data can be determined based on the coefficient value $\left(R^{2}\right)$. In this case, the $R^{2}$ (multiple correlation coefficient) was equal to 0.5642 , which indicated that $56.42 \%$ of the variability in the response could be explained by the second- order polynomial prediction equation given above. The normal probability and studentized residuals plot were shown in Fig. 2. This figure revealed that how well the model satisfies the assumption of ANOVA where the studentized residuals measured the number of standard deviations separating the actual and predicted value.

\subsection{Effect of variable}

In order to determine the optimal level of each variable for production of KAMO, three-dimensional (3D) response surface plots were constructed by ploting the response (percentage conversion) on the $\mathrm{Z}$-axis against any two dependent variables, while maintaining other variables at their optimal levels. Among the various treatments, the greatest percentage conversion $(37.21 \%)$ was achieved with treatment $7\left(42 \mathrm{~h}, 52.5^{\circ} \mathrm{C}\right.$ and $0.17 \mathrm{~g}$ amount of enzyme) and the smallest ( $0 \%)$ with treatment $5\left(36 \mathrm{~h}, 30^{\circ} \mathrm{C}\right.$

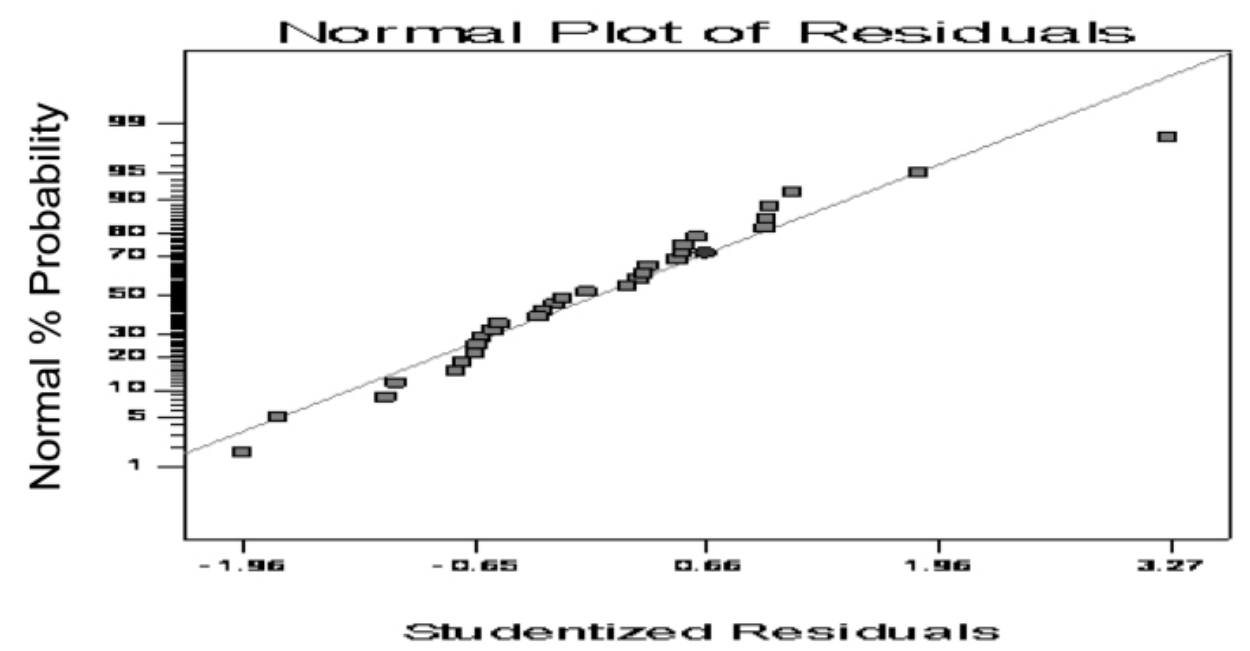

Fig. 2 The Plot Adsorption of Kojic Acid Monooleate: The Studentized Residuals and Normal Probability Plot. 


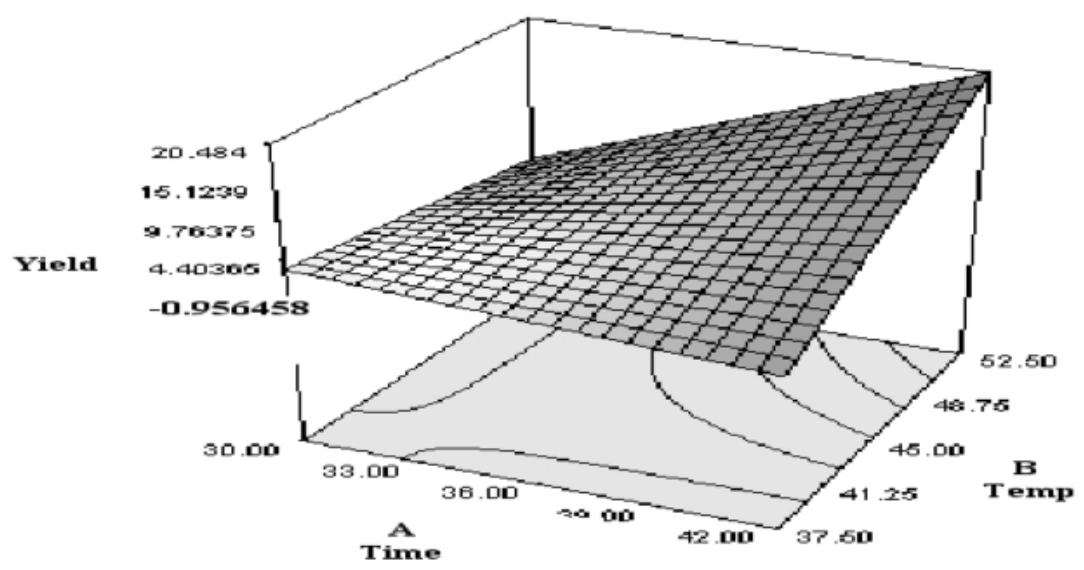

Fig. 3 The Combine Effects of Time (A) and Temperature (B) on Kojic Acid Ester Production.

(Enzyme amount was fixed at $0.17 \mathrm{~g}$ ).

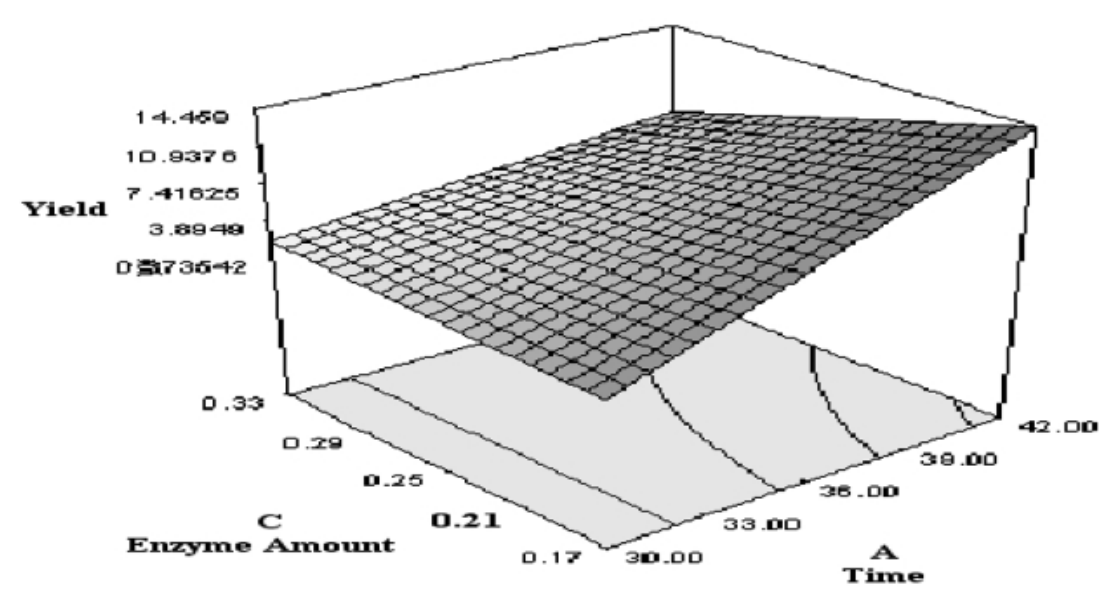

Fig. 4 The Combined Effect of Enzyme Amount (C) and Time (A) on Kojic Acid Ester Production.

(Temperature was fixed at $52.5^{\circ} \mathrm{C}$ ).

and $0.25 \mathrm{~g}$ amount of enzyme).

Figure 3 depicts the linear response surface plot as a function of reaction time (A) versus reaction temperature (B).The amount of enzyme (C) was fixed at their center point $(0.17 \mathrm{~g})$. The highest yield $(37.21 \%)$ was obtained at $42 \mathrm{~h}$ of reaction time and $52.5^{\circ} \mathrm{C}$ temperature, whereas at higher reaction time $(48 \mathrm{~h})$ and moderate temperature $\left(45^{\circ} \mathrm{C}\right)$ using $0.25 \mathrm{~g}$ of enzyme, the production of KAMO was quite low (treatment 4 with the yield of $2.63 \%$ ). It is clear that prolonging the reaction time increases the volume of water (byproduct) produced by the reaction and thus may reduce the percentage yield of product ${ }^{14-16}$. The conversion of kojic acid ester was increased by increasing the temperature up to $52.5^{\circ} \mathrm{C}$. When the temperature was raised up to $60^{\circ} \mathrm{C}$, the yield was drastically decreased. That was probably because beyond a critical temperature, the lipase is not active anymore or deactivated ${ }^{17-19)}$.

Figure 4 represents the effect of varying the amount of enzyme (C) and reaction time (A) on the formation of kojic acid monooleate. The reaction temperature $(\mathrm{B})$ was fixed at $52.5^{\circ} \mathrm{C}$. According to the P-value ( $\left.>>0.05\right)$, the amount of enzyme was less significant compare to reaction time and temperature. The highest yield of KAMO (37.21\%) was achieved with $0.17 \mathrm{~g}$ of enzyme at $42 \mathrm{~h}$ of reaction time. Whereby, at the highest amount of enzyme $(0.40 \mathrm{~g})$ and moderate reaction time $(36 \mathrm{~h})$, the percent conversion was drastically decreased (5.54 \%) as depicted in the treatment 16. At this point, all substrates are bound to the enzyme and further addition of any enzyme molecules in the reaction may cause a decrease in the yield due to the substrate limitations. The lower yield may also be due to the steric hinderance produced by an excessive enzyme which lead 


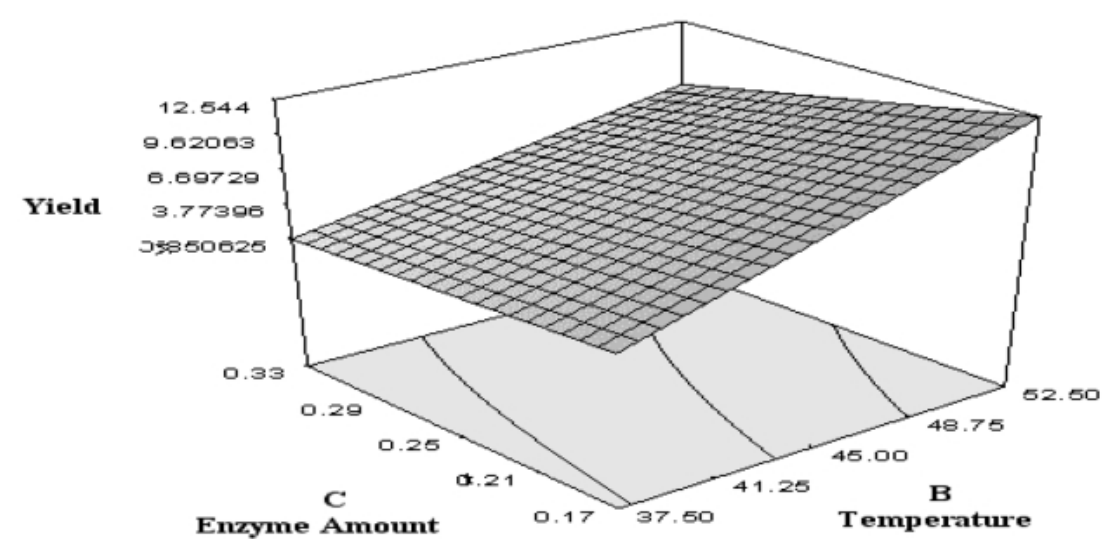

Fig. 5 The Combined Effect of Enzyme Amount (C) and Temp (B) on Kojic Acid Ester Production . (Time was fixed at $42 \mathrm{~h}$ ).

to a more condense mixture and contribute to the decreasing of reaction rate $^{20}$. This report helps in explaining that the excess enzyme used did not contributed to increase the yield of the percent conversion. From an economic viewpoint, it would be desirable to use the lowest amount of enzyme to achieve maximum conversion of KAMO. In 2002, Chen and colleges studied the effect of enzyme load on enzymatic synthesis of kojic acid and lauric acid ${ }^{21}$. They agree that the higher load of enzyme in the reaction led to higher product yield, which may due to the substrate limitation and the enzyme itself could also caused mass transfer limitation.

The effect of enzyme amount $(\mathrm{C})$ and reaction temperature (B) on the production of kojic acid monooleate is shown in Fig. 5 as a linear response surface plot. An optimum point of maximum product yield obtained $37.21 \%$ at $0.17 \mathrm{~g}$ enzyme amount and with temperature of $52.5^{\circ} \mathrm{C}$ by fixing the time at $42 \mathrm{~h}$. At low amount of enzyme and high reaction temperature, high percentage yield was achieved. It is important to note that the effect of reaction time and reaction temperature on the esterification yield is more important than the amount of enzyme. However, enzyme can be reused leading to cost savings. This is an indicator of effectiveness and economical performance. From the result, we can say that there was about $20 \%$ improvement of the percentage conversion of KAMO by using RSM (37 $\%)$ as compared to the previous studied ${ }^{11)}$ by using conventional method (11\%).

\section{CONCLUSION}

In this study, we focuses on the effects of operating variables such as enzyme amount, reaction time and reaction temperature. We used RSM to better understand the relationship between those variables and have demonstrated that optimum synthesis of kojic acid ester can be successfully predicted by RSM. An understanding of optimization via conventional methods of individual effects in the previous work and interactive effects by RSM as reported in this paper will provide valuable information for future upscaled enzymatic production of kojic acid ester by considering all of the environmental and economical evaluations. In addition, the chemical structure of kojic acid monooleate was revealed by using TLC, FT-IR and GC spectroscopy.

\section{ACKNOWLEDGEMENT}

We acknowledge the financial support from Science Fund, the Ministry of Science, Technology and Innovation of Malaysia, Project reference: 02-01-04-SF0238 and National Scholarship Fund (NSF) for Siti Efliza Ashari.

\section{References}

1. Le Blanch, D.T.; Akers, H.A. Maltol and ethyl maltol from larch tree to successful food additives. J. Food Technol. 26, 78-87 (1989).

2. Ichimoto, I.; Itaoka, Y.; Tatsumi, C. Studies on kojic acid and its related $\gamma$-pyrone compounds-XI. Agr. Biol. Chem. Tokyo 22, 841 (1965).

3. Cabanes, J.; Chazarra, S.; Gracia, F. Kojic acid, a cosmetics skin whitening agent, is a slow-binding inhibitor of catecholase activity of tyrosinase. J. Pharmaceut. Pharmocol. 46, 982-985 (1994).

4. Kinosita, R.; Shikata, R. Toxic moldy rice, in Mycotoxins in Foodstuffs, Wogan GN, MIT Press, Cambridge, MA. 42,111-132 (1964).

5. Chen, J.S.; Wei, C.; Marshall, M.R. Inhibition mecha- 
nism of kojic acid on polyphenol oxidase. J. Agric. Food Chem. 39, 1897-1901 (1991).

6. Nagai, S.; Izumi. T. United State Pat. 124115-124116 (1983).

7. Awang, R.; Basri, M.; Ahmad, S.; Salleh, A.B. Enzymecatalyzed synthesis and characterization of octyl dihydroxystearate from palm-based dihydroxystearic acid. J. Oleo Sci. 52, 7-14 (2003).

8. Yadav, G.D.; Lativ, P.S. Kinetics and mechanism of synthesis of butyl isobutyrate over immobilised lipases. $J$. Biochem. Eng. 16, 245-252 (2003).

9. Vicenta, M.; Aracil, J.; Martinez, M. Biocatalytic processes for the production of fatty acid esters. Brew Symposium, Madrid. (2005).

10. Liu, K.J.; Shaw, J.F. Lipase-catalyzed synthesis of kojic acid esters in organic solvents. J. Am. Oil Chem. Soc. 75, 1507-1511 (1998).

11. Kamarudin, N.H.; Basri, M.; Cheng Lian, G.; Salleh, A.B.; Abdul Rahman, R.N.Z.; Ariff, A.; Mohamad, R. Enzymatic synthesis and characterization of palmbased kojic acid ester, J. Oil Palm. 20, 461-468 (2008).

12. Mune, M.A.M.; Minka, S.R.; Mbome, I.L. Response surface methodology for optimization of protein concentration preparation from cowpea (Vigna unguiculata $(L)$ Walp). J. Food Chem. 110, 735-741 (2008).

13. Kim, B.H; Akoh, C.C. Modeling and optimization of lipase-catalyzed synthesis of phytosteryl esters of oleic acid by response surface methodology. Food Chem. 102, 336-342 (2007).

14. Mat Radzi, S.; Basri, M.; Salleh, A.B.; Ariff, A.; Mohamad, R.; Abdul Rahman, M. B.; Abdul Rahman,
R.N.Z. Optimization study of large scale enzymatic synthesis of liquid wax ester by response surface methodology. J. Chem. Technol. Biotechnol. 81, 374-380 (2005).

15. Villeneuve, P.; Barea, B.; Sarrazin, P.; Davrieux, F.; Boulanger, R.; Caro, Y. Synthesis of pyroglutamic acid fatty esters though lipase-catalyzed esterification with medium chains alcohols. Enzy. Microb. Technol. 33, 7984 (2003).

16. Soo, E.L.; Salleh, A.B.; Basri, M.; Abdul Rahman, R.N.Z.; Kamarudin, K. Response surface methodology study on lipase-catalysed synthesis of amino acid surfactants. Proc. Biochem. 39, 1511-1518 (2003).

17. Mat Radzi, S.; Basri, M.; Salleh, A.B.; Ariff, A.; Mohamad, R.; Abdul Rahman, M. B.; Abdul Rahman, R.N.Z. Large scale production of liquid wax ester by immobilized lipase. J. Oleo Sci. 54, 203-209 (2005).

18. Yankah, V.V.; Akoh, C.C. Lipase-catalyzed acidolysis of tristearin with oleic or caprylic acids to produce structured lipids. J. Am. Oil Chem. Soc. 77, 495-500 (2000).

19. Hirata, H.; Higuchi, K.; Yamashina, T. Lipase-catalyzed transesterification in organic solvent. Effect of water and solvents, thermal stability and some applications. Biotechnol. 14, 151-167 (1990).

20. Mat Hadzir, N.; Basri, M.; Abd Rahman, B.; Abdul Razak, C.N.; Abd Rahman, R.N.Z; Salleh, A.B. Enzymatic alcoholysis of triolein to produce wax ester. J. Chem. Technol. Biotechnol. 76, 511-515 (2001).

21. Chen, C. S.; Liu, K.J.; Lou, Y.H.; Shieh, C.J. Optimization of kojic acid monolaurate synthesis with lipase PS from Pseudomonas cepacia. J. Sci. Food Agric. 82, 601-605 (2002). 